\title{
Web Engineering Sistem Informasi Pelayanan Pengaduan Online Pada P2TP2A Provinsi Lampung
}

\author{
${ }^{1}$ Suaidah, ${ }^{2}$ Lathifah $\&{ }^{3}$ L.M.Aldo Duarsa $S$ \\ 1,2,3 Sistem Informasi, Universitas Teknokrat Indonesia, Jl. Z.A Pagaralam No. 9-11, Bandar Lampung, Indonesia \\ e-mail : ${ }^{1}$ suaidah@teknokrat.ac.id, ${ }^{2}$ lathifah@teknokrat.ac.id, ${ }^{3}$ aldoduarsa.ad@gmail.com
}

\begin{abstract}
P2TP2A is an institution that provides services to protect women and children such as domestic violence, abuse, child sexual violence, etc. The complaints mechanism is carried out by means of the community coming directly, contacting by telephone and can be represented by the family. The first obstacle that was obtained during the reporting process was if the victim did not dare to come directly and kept his address a secret, so that the P2TP2A would have difficulty doing surveys, education and direct services with the victim. The second obstacle was the severed communication access and often the victim did not include the telephone number when reporting. The third obstacle is that people complain about the distance from home to $\mathrm{P} 2 \mathrm{TP} 2 \mathrm{~A}$ which is far enough so that it requires funds and transportation to come to P2TP2A. Other constraints $\mathrm{P} 2 \mathrm{TP} 2 \mathrm{~A}$ does not yet have a symphony of data that can record victim registration, reporting of public complaints and service processes, so it has not been able to increase productivity in the public eye.

The purpose of this research is to reach all aspects of public services, namely helping the public to submit complaints, manage information, consultancy services, and outreach to the public using web engineering. The stages of the research method were carried out by analyzing the event, collecting data, reviewing the literature, studying the literature, designing, implementing, testing, analyzing the results of the prototype and making the Application handbook. It is hoped that the results of this research will enable the system to be well integrated and centralized to become one, helping $\mathrm{P} 2 \mathrm{TP} 2 \mathrm{~A}$ to serve complaints from the public online easily, quickly and at any time.
\end{abstract}

Keywords: Pengaduan; Pelayanan Masyarakat; Web Engineering.

\section{PENDAHULUAN}

Perkembangan teknologi informasi menghasilkan beberapa perangkat yang dapat membantu menyelesaikan pekerjaan dengan sangat mudah, instansi dan organisasi saat ini banyak menggunakan teknologi dalam menyelesaikan pekerjaan tersebut, salah satunya dalam memberikan pelayanan-pelayanan menggunakan sistem dalam memberikan informasi kepada pelanggan yang membutuhkan dan mendapatkan informasi [2]. P2TP2A-LIP adalah salah satu wahana pelayanan bagi perempuan dan anak dalam upaya pemenuhan informasi dan kebutuhan di bidang pendidikan, kesehatan, ekonomi, politik, hukum, perlindungan dan penanggulangan tindak kekerasan serta perdagangan terhadap perempuan dan anak. Dibentuk sesuai dengan Keputusan Gubernur Lampung Nomor : G/3456/B.VIII/HK/2002, tentang Pembentukan Pengurus P2TP2A. Pelayanan publik adalah segala kegiatan pelayanan yang dilaksanakan oleh penyelenggara pelayanan publik sebagai upaya pemenuhan kebutuhan penerima layanan maupun pelaksanaan ketentuan peraturan perundangundangan [4]. Peningkatan pelayanan publik adalah salah satu reformasi birokrasi peningkatan pelayanan masyarakat. Kuliatas pelayanan publik yang terjadi masih kurang maksimal, hal ini dapat dilihat berdasarkan banyaknya pengaduan masyarakat terhadap kualitas pelayanan publik yang diajukan secara langsung kepada unit pelayanan publik dan petugasnya [1].

P2TP2A adalah lembaga yang menyediakan pelayanan perlindungan perempuan dan anak seperti KDRT, penganiayaan, kekerasan seksual anak dll. Berdasarkan hasil wawancara kepada Ibu Tri Apriani dengan jabatan sebagai pendamping korban dan pengurus proses kegiatan pengaduan pelayanan didapatkan kondisi mekanisme pengaduan dilakukan dengan cara masyarakat datang langsung, menghubungi melalui telpon dan bisa diwakili oleh keluarga. Kendala pertama yang didapat pada saat proses pelaporan ialah bila korban tidak berani datang langsung serta merahasiakan alamatnya, dengan begitu pihak P2TP2A akan mengalami kesulitan 
untuk melakukan survei, edukasi dan pelayanan langsung pada korban. Kendala kedua terputusnya akses komunikasi dan sering terjadi korban tidak mencantumkan nomor telpon pada saat melapor. Kendala ketiga ialah masyakarat mengeluhkan karna jarak tempuh dari rumah ke P2TP2A yang cukup jauh sehingga membutuhkan dana dan transportasi untuk datang ke P2TP2A. Masyarakat setiap waktu menuntut pelayanan publik yang berkualitas, meskipun tuntutan tersebut sering tidak sesuai dengan harapan, karena pelayanan publik harus melalui prosedur, proses tahap demi tahap serta dibutuhkan pengoreksian data dukung guna keakuratan data setiap penduduk sehingga yang terjadi selama ini masih berkesan berbelit-belit, lambat, dan melelahkan. Kendala lainnya pihak P2TP2A belum memiliki simfoni data (sistem informasi online) yang dapat mendata pendaftaran korban, pelaporan pengaduan masyakarat dan proses pelayanan, sehingga belum mampu meningkatkan produktivitas di mata publik.

Komplain Masyarakat adalah kualitas suatu pelayanan jasa harus dimulai dari keinginan masyarakat dan berakhir pada pendapat dari pelanggan. Hal tersebut menjadikan citra kualitas yang maksimal bukan berdasarkan sudut pandang atau pendapat dari pihak penyedia layanan jasa namun, berdasarkan pendapat dari masyarakat. Pendapat pelanggan terhadap kualitas layanan jasa adalah penilaian menyeluruh suatu pelayanan. Tetapi, perlu dikhawatirkan bahwa kinerja pelayanan seringkali tidak konsisten. Jika masyarakat mengadu karena tidak puas maka mereka merasa pelayanannya tidak sesuai dengan harapan. Dengan demikian, semakin meningkat harapan permintaan seorang pelanggan, semakin besar pula kemungkinan ia tidak puas terhadap layanan jasa yang diterima [5].

Penelitian terdahulu menjelaskan dengan judul sistem pelayanan pengaduan online berbasis web pada PT.Fira informatika untuk meningkatkan layanan konsumen. Penelitian ini membahas tentang cara menentukan tingkat efektivitas aplikasi pengaduan online berbasis web dalam melayani pengaduan konsumen atau klien di Kelurahan PT. Fira Informatika Semarang. Instrumen yang dipergunakan dalam pengumpulan data adalah: kuisioner, lembar observasi dan pedoman wawancara. Dari penelitian ini memperoleh hasil analisis setelah melakukan pengujian menggunakan Uji Kolmogorov-Smirnov. Hasil pengujian hipotesis menunjukan bahwa nilai Mean Rank sebesar 168, 900 menunjukan bahwa aplikasi pengaduan ini berjalan efektif dalam penanganan pengaduan konsumen, sedangkan sisanya sebesar 150, 2600 menunjukan besar rata-rata pengaduan manual [3].

Sistem Layanan Pengaduan Masyarakat Lingkup Desa Gunungtanjung Berbasis Web Dan Sms Gateway Dengan Metode Antrian Fifo. Penelitian ini membahas tentang Pemerintah Desa Gunungtanjung membangun sistem layanan pengaduan masyarakat ini diharapkan akan mengatasi segala permasalahan pengaduan masyarakat. Sistem informasi yang dibuat menggunakan fasilitas SMS Gateway yaitu aplikasi ini menggunakan model SMS dua arah dimana antara pengguna dan aplikasi bisa saling mengirim pesan untuk menerima pengaduan dari masyarakat. Selanjutnya, masyarakat mengirim pesan singkat melalui handphone dan aplikasi akan menerima pengaduan masyarakat tersebut. Setiap pengaduan yang masuk akan ditampilkan pada website secara publik sehingga besar harapan untuk mendapatkan respon dari pihak Pemerintah Desa Gunungtanjung [1].

Tujuan dari penelitian ini adalah membangun aplikasi yang bisa menjangkau semua aspek pelayanan publik, yaitu pengelolaan pengaduan masyarakat, pengelolaan informasi, pelayanan konsultasi, dan penguluhan kepada masyarakat menggunakan web engineering. Teknologi web engineering dapat menampilkan keterangan informasi pelayanan publik yang jelas agar masyarakat mendapatkan pelayanan yang baik dan dapat melakukan pengaduan mengenai fasilitas, pelayanan yang kurang baik, dan meningkatkan daya guna pelaksanaan fungsi-fungsi pelayanan oleh pemerintah melalui sarana yang mumpuni, demi peningkatan efektivitas, efisiensi dan produktivitasnya.

\section{METODOLOGI PENELITIAN}

Metodologi penelitian pada dasarnya adalah kerangka hubungan antara konsep-konsep yang ingin diamati atau diukur melalui penelitian yang akan dilakukan. Permasalahan tersebut tentu menjadi perhatian dalam seluruh entitas yang terdapat di dalamnya. Tahapan metodologi penelitian dapat dilihat pada Gambar 1. 


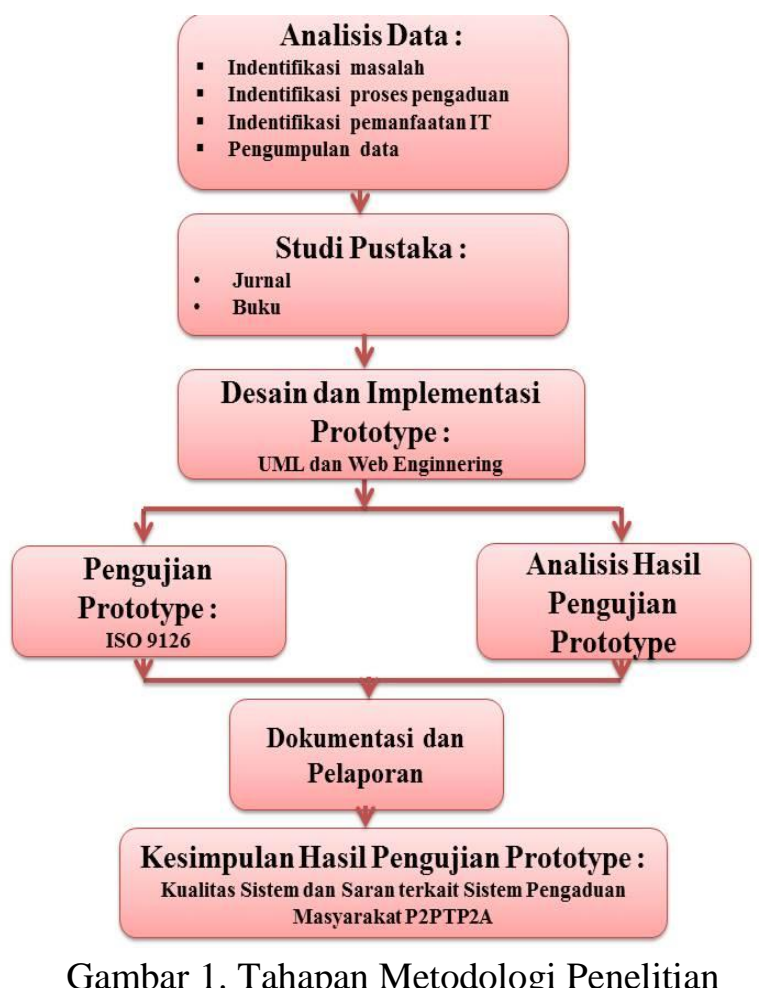

Berikut penjelasan dari gambar Tahapan Metodologi Penelitian

1. Analisis Data

Langkah ini bertujuan untuk mengetahui data pelayanan masyarakat. Analisis data ini merupakan salah satu metode pengumpulan data yang dalam penelitian ini dilakukan dengan teknik observasi.

2. Studi Pustaka

Penelitian ini dimulai dengan melakukan studi pustaka yang berkaitan dengan data pelayanan Publik, Unsur-unsur pelayanan masyarakat, komplain masyarakat, dan web. Serta dengan mengutip jurnal-jurnal penelitian dan buku yang terkait.

3. Rancangan dan Implementasi Prototype

Langkah selanjutnya adalah membuat rancangan yang berkaitan dengan perancangan dan pembuatan aplikasi web engineering pengaduan pelayanan masyarakat. Adapun rancangan sistem menggunakan use case yang menggambarkan bagaimana sistem akan dijalankan oleh para aktor atau user dan implementasi data web engineering pengaduan pelayanan masyarakat.

4. Pengujian Prototype

Pada tahap ini peneliti melakukan simulasi dan pengujian yaitu terhadap aplikasi yang telah dibuat. Adapun pengujian ini dilakukan untuk melihat apakah ada kesalahan dengan aplikasi yang telah dibuat.

5. Analisis Hasil Pengujian Prototype

Melakukan pengamatan evaluasi dari hasil simulasi dan pengujian yang sudah dilakukan.

6. Dokumentasi dan Pelaporan

Tahapan ini bertujuan mendokumentasikan semua hasil dari penelitian dan melaporkan kepada pihak-pihak terkait.

7. Kesimpulan Hasil Pengujian Prototype

Penarikan kesimpulan ini bertujuan untuk menjelaskan kesesuaian hasil rancangan untuk diterapkan pada aplikasi web engineering pengaduan pelayanan masyarakat.

\subsection{Use Case Diagram}

Use case perancangan sistem pengaduan pelayanan masyarakat P2PTP2A Provinsi Lampung dapat dilihat pada Gambar 2. 
(C2020 Ilmu Komputer Unila Publishing Network all rights reserved

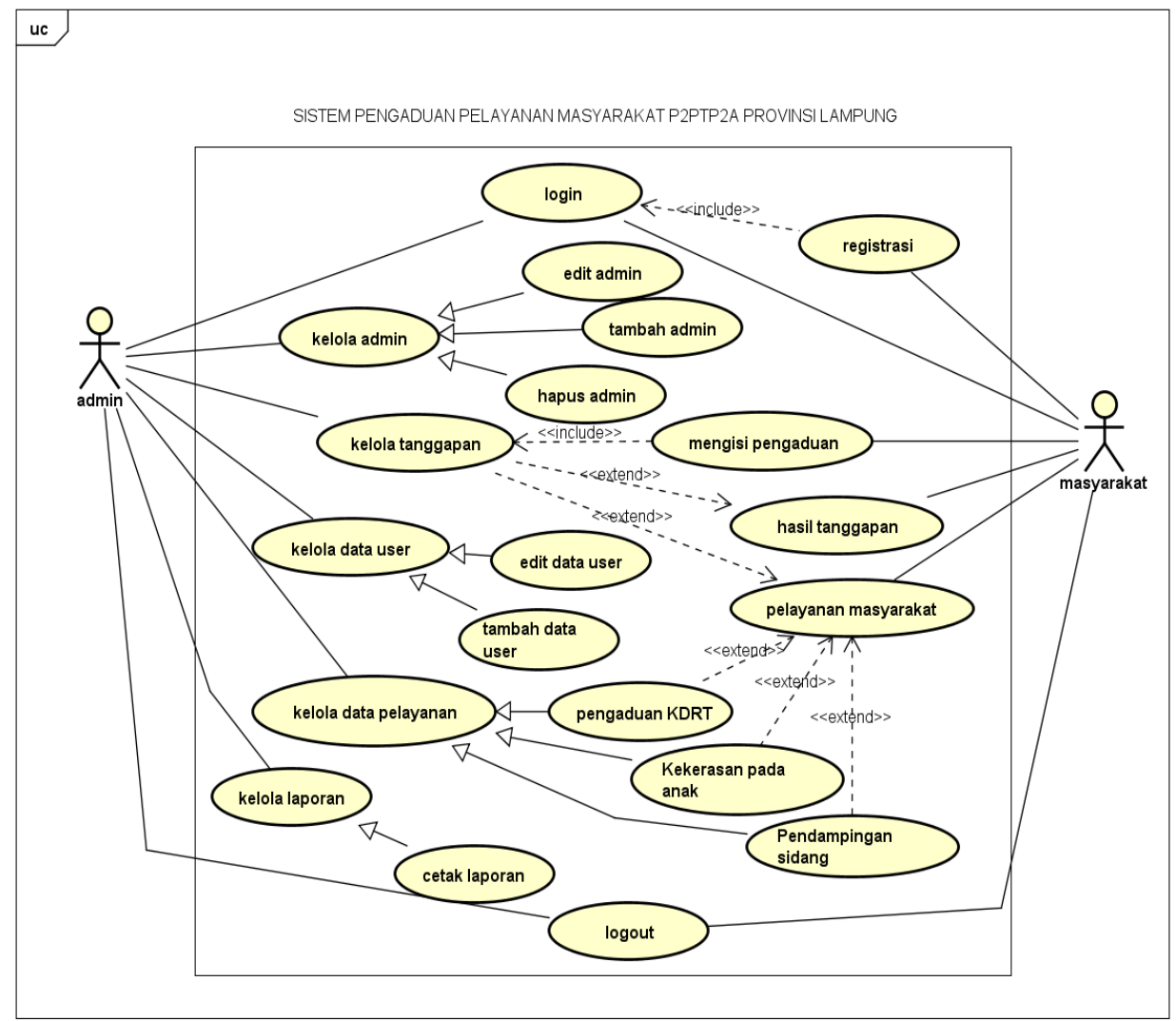

Gambar 2. Use Case Diagram

\subsection{Arsitektur Web}

Arsitektur web sistem pengaduan pelayanan masyarakat P2PTP2A Provinsi Lampung dapat dilihat pada Gambar 3.

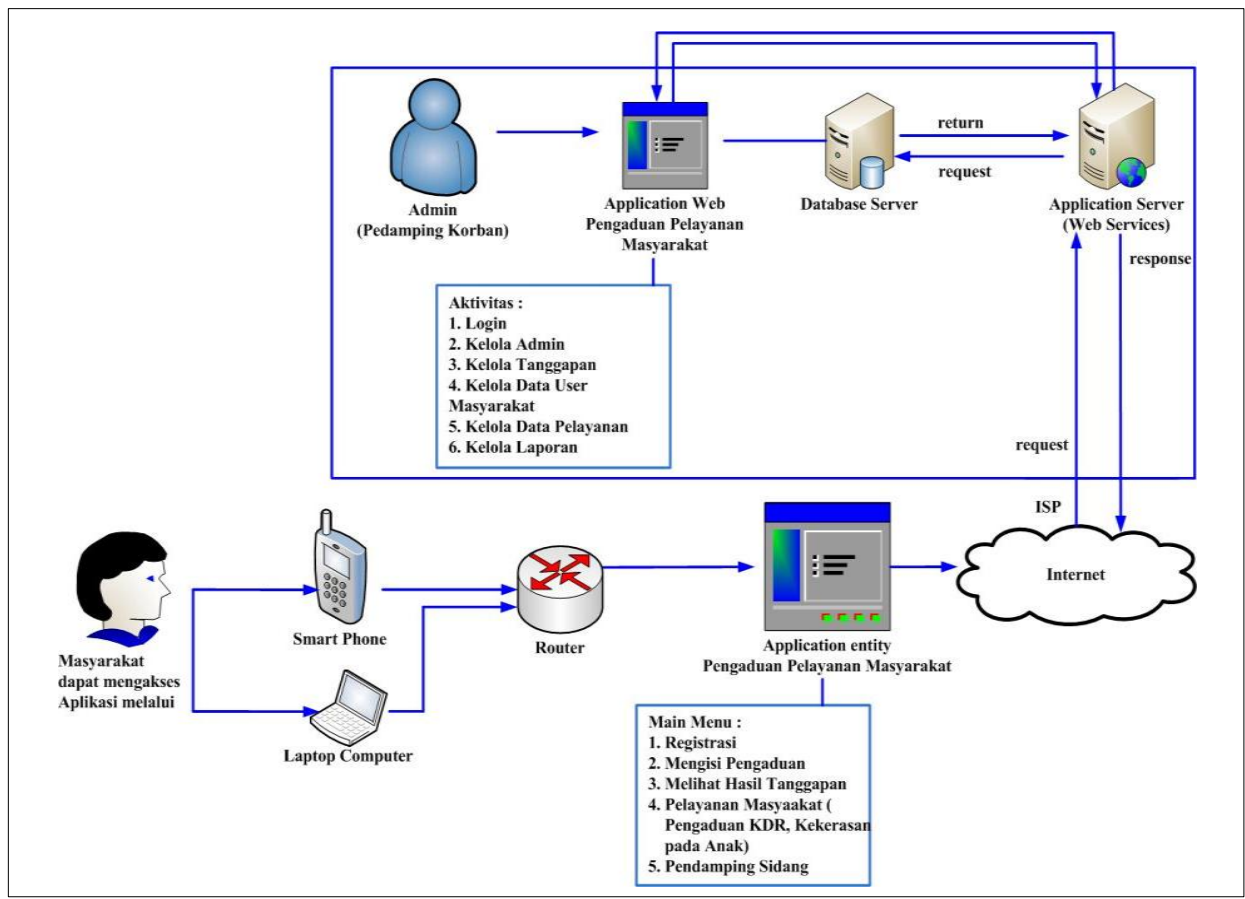

Gambar 3. Arsitektur Web Engineering Pengaduan pelayanan masyarakat 
(C2020 Ilmu Komputer Unila Publishing Network all rights reserved

\section{Jurnal Komputasi}

\section{HASIL DAN PEMBAHASAN}

\subsection{Tampilan Administrator}

\subsubsection{Tampilan Login}

Halaman login merupakan tampilan ketika sistem akan dijalankan, login harus dilakukan pengguna untuk masuk ke dalam sistem. Halaman login dapat dilihat pada Gambar 4.

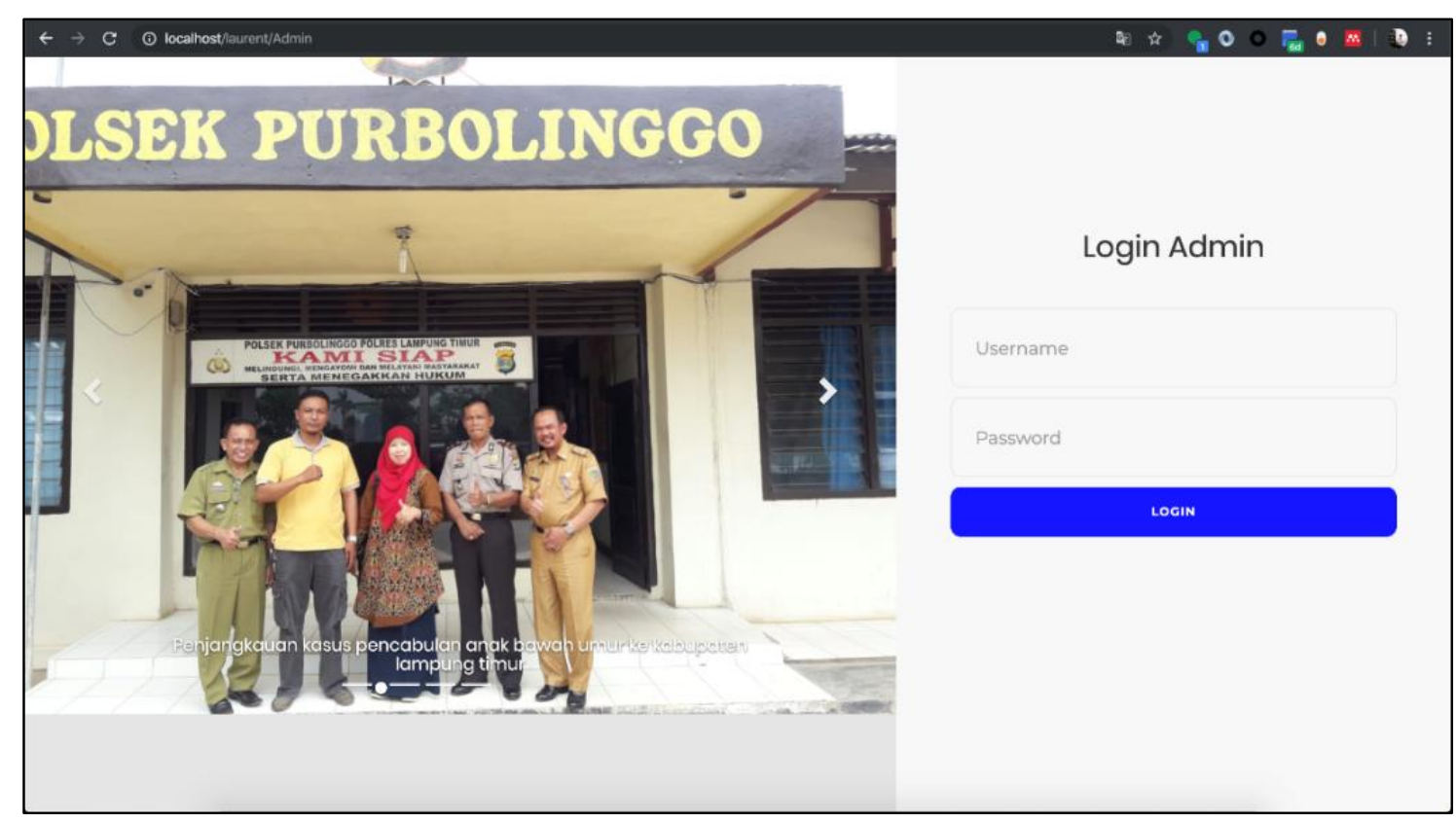

Gambar 4. Tampilan Halaman Login

\subsubsection{Tampilan Halaman Kelola Admin}

Halaman kelola admin dapat melakukan edit admin dan menambahkan admin baru agar dapat mengakses sistem tersebut. Halaman kelola admin dapat dilihat pada Gambar 5. 


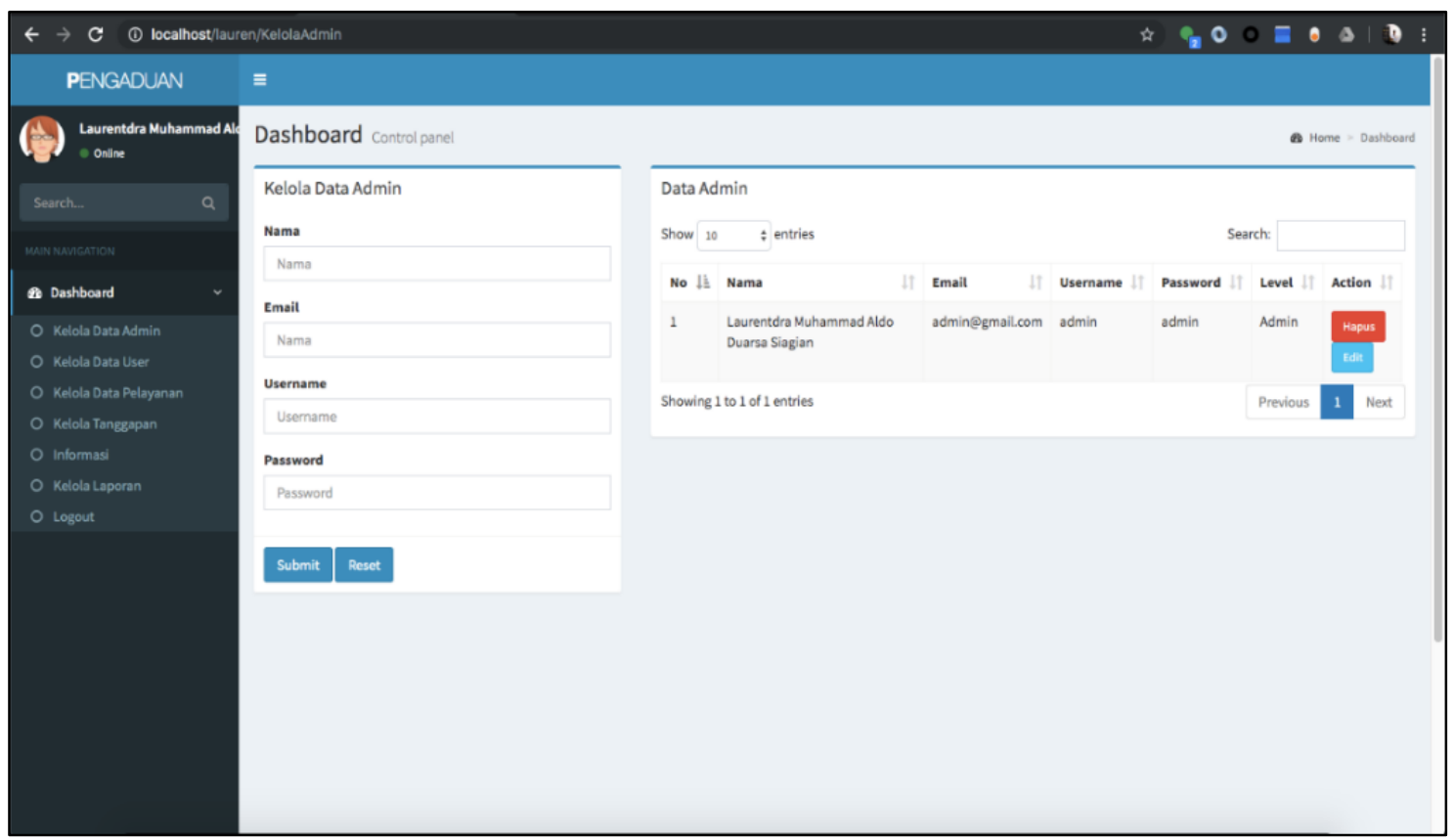

Gambar 5. Halaman kelola admin

\subsubsection{Tampilan Halaman Pelayanan}

Halaman pelayanan dapat menambahkan data pelayanan yang baru . Tampilan halaman pelayanan dapat dilihat pada Gambar 6.

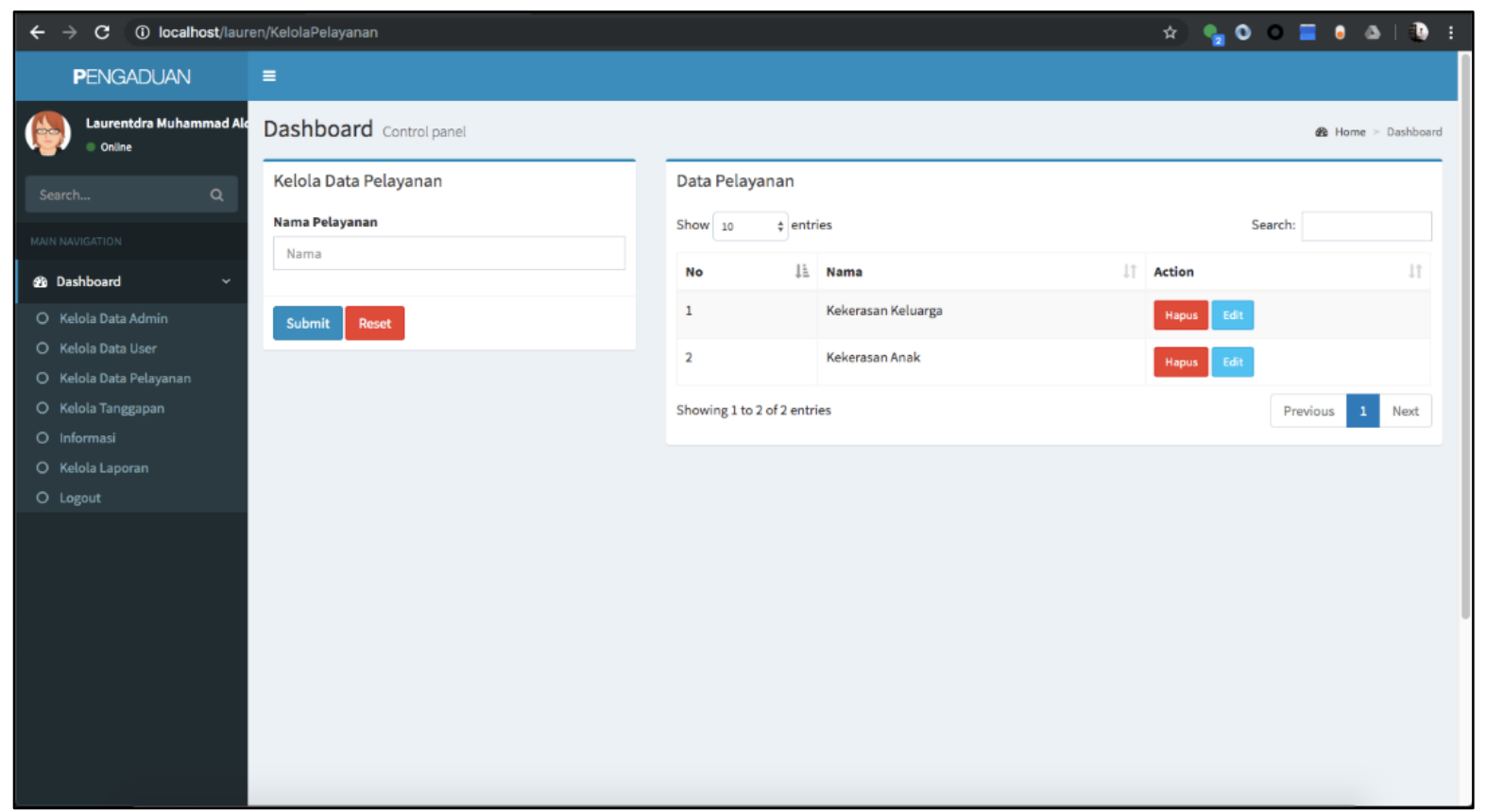

Gambar 6. Tampilan Halaman Pelayanan

\subsubsection{Tampilan Halaman Tanggapan}

Halaman tanggapan adalah memberikan balasan kepada masyarakat terhadap pengaduan yang masyarakat kepada pihak P2TP2A. Tampilan halaman tanggapan dapat dilihat pada Gambar 7.

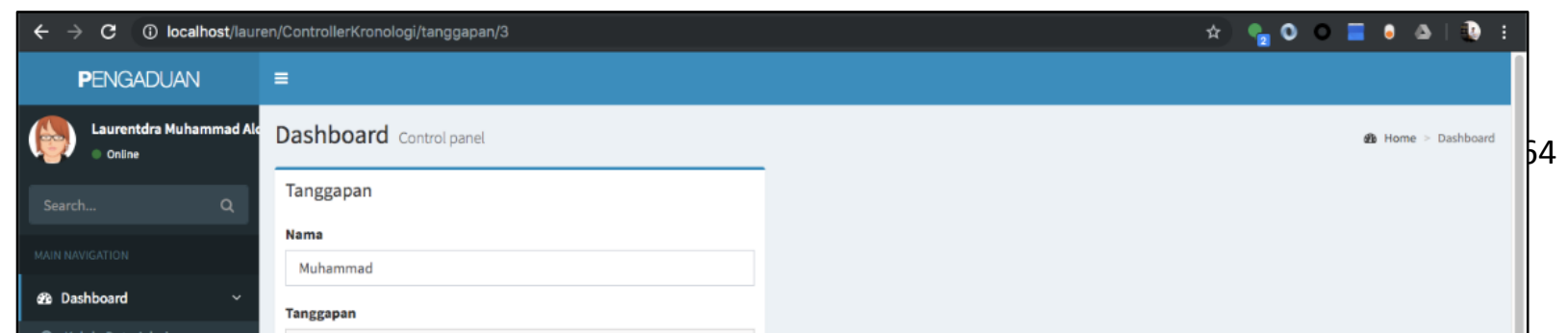




\subsection{Tampilan User}

\subsubsection{Tampilan Halaman Kronologi}

Tampilan kronologi menampilkan penginputan pengaduan yang diinputkan oleh user sesuai dengan jenis pelayanan yang dibutuhkan oleh user. Tampilan kronologi dapat dilihat pada Gambar 8.

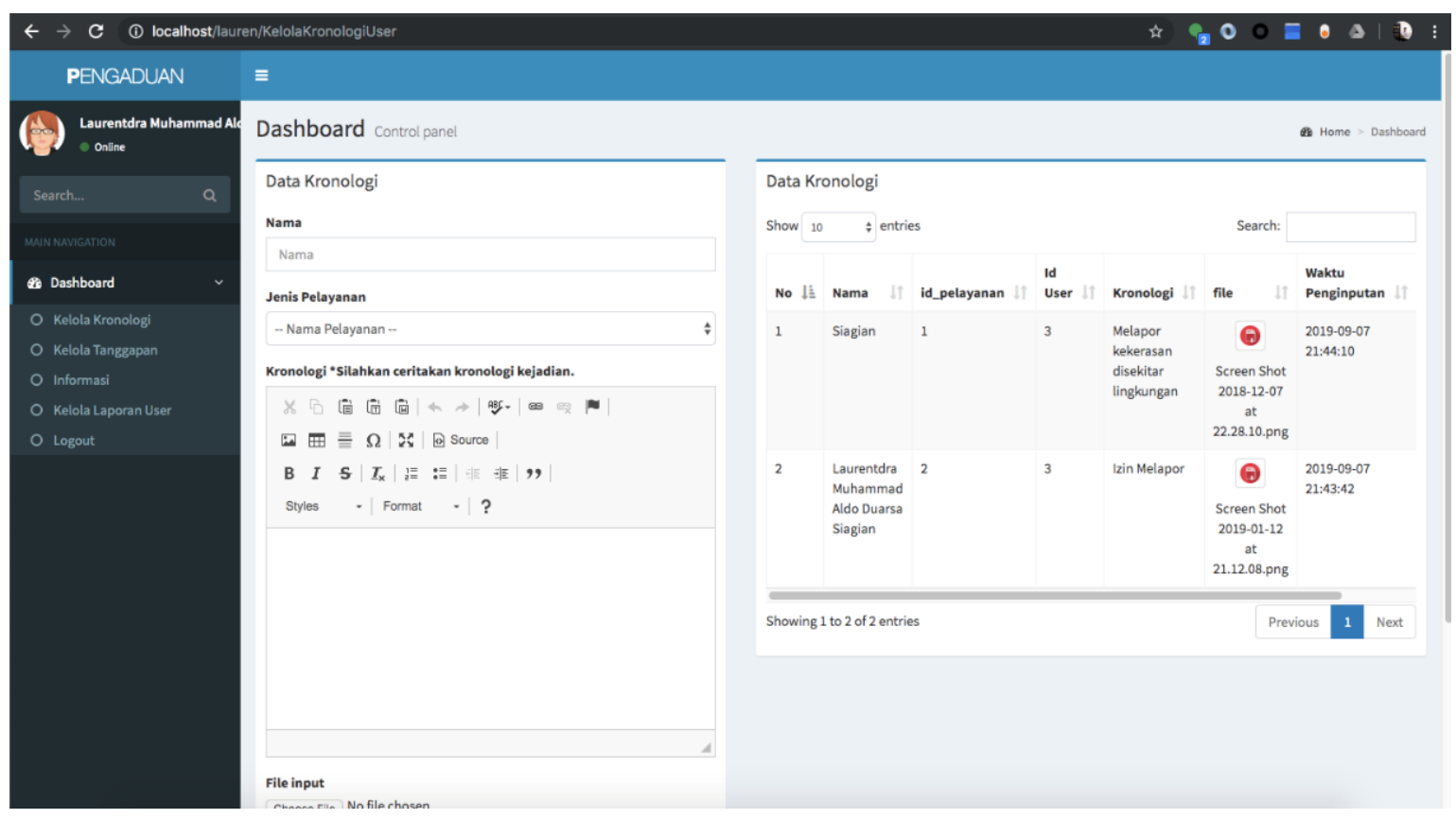

Gambar 8. Tampilan Halaman Kronologi

3.2.2. Tampilan Halaman Laporan

Tampilan laporan menampilkan hasil dari tanggapan. Tampilan laporan dapat dilihat pada Gambar 9. 


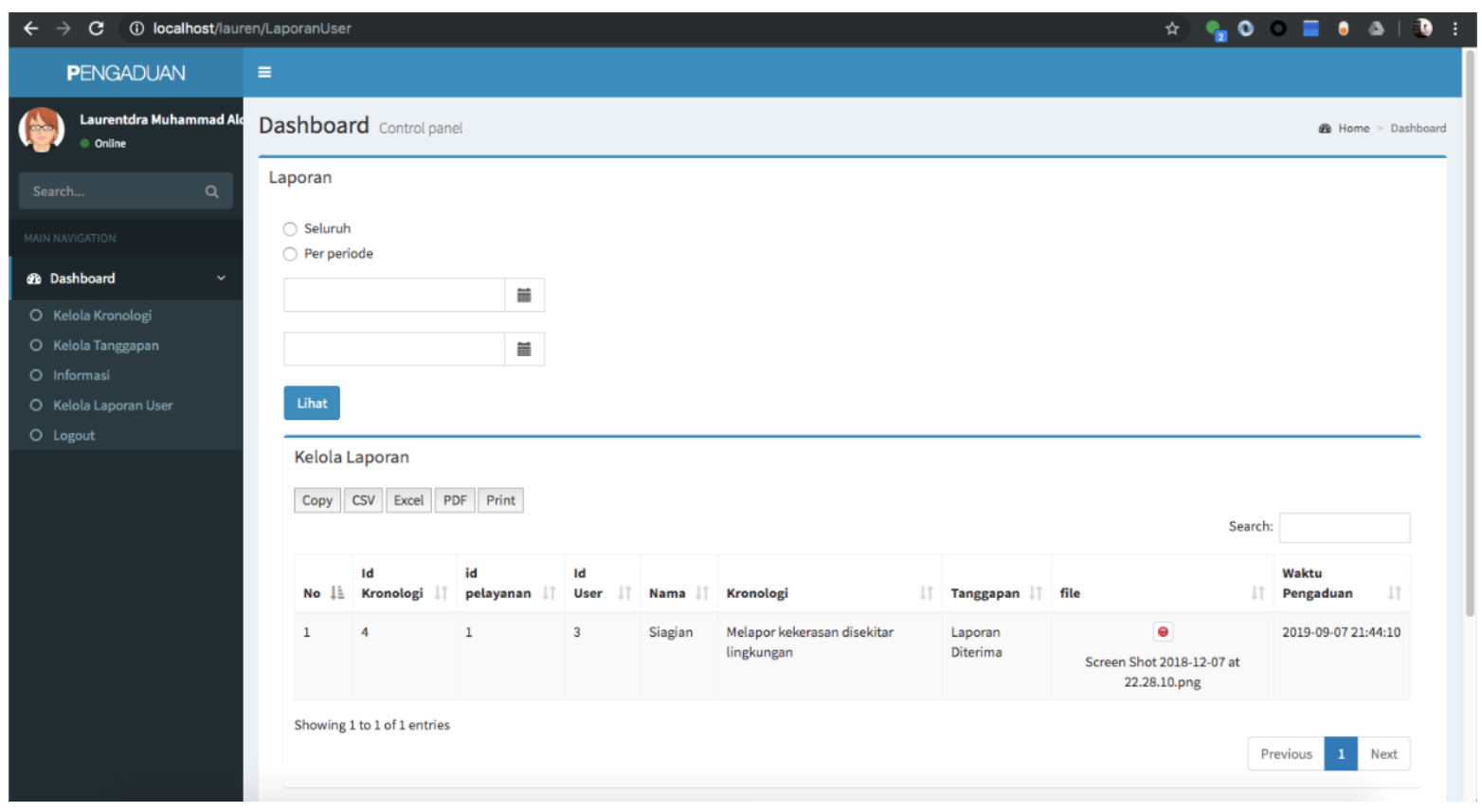

Gambar 9. Tampilan Halaman Laporan

\subsection{Pengujian Sistem ISO 9126}

Tahap testing dilakukan setelah tahap pembuatan dengan menjalankan sistem dan melihat apakah ada kesalahan atau tidak pada pengujian sistem web engineering sistem informasi pelayanan pengaduan online.

\subsubsection{User Acceptance Test}

Hasil pengujian ini diisi oleh calon user sebagai pengguna sistem. Jumlah responden dalam pengujian sistem ini yaitu 15 peserta sebagai responden. Hasil perhitungan skor per 5 kategori penilaian :

1. Penilaian terhadap Aspek Rekayasa Perangkat Lunak

Tabel 1. Penilaian Aspek Rekayasa Perangkat Lunak

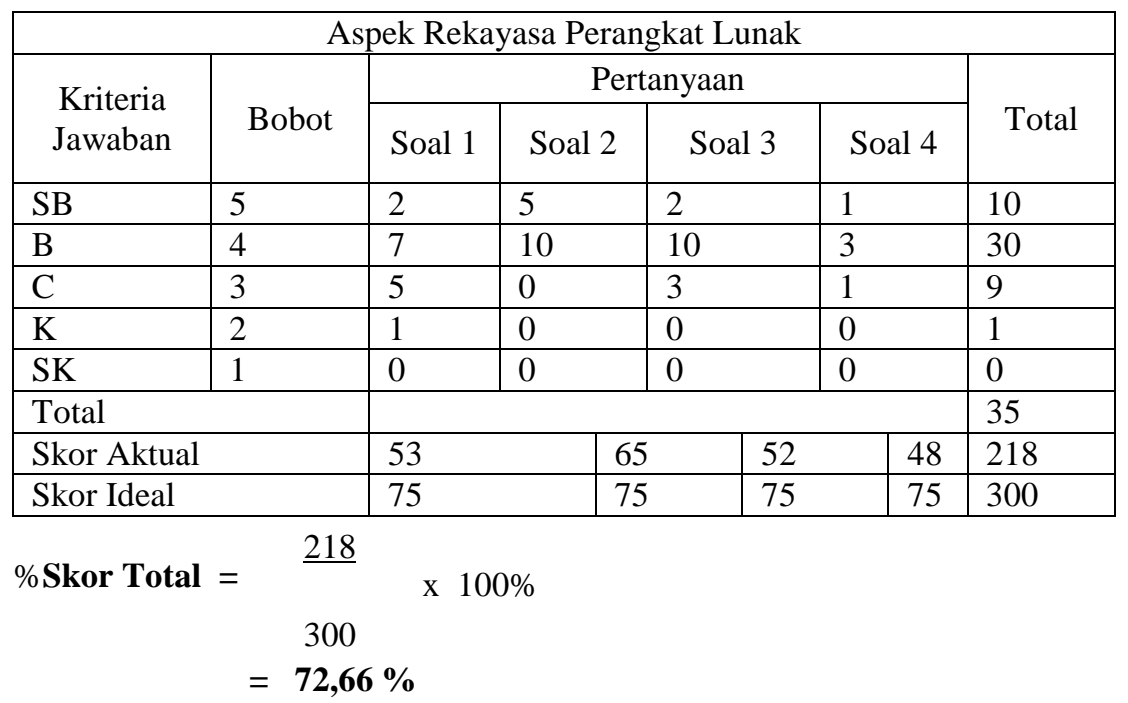

Dari hasil pengolahan data tanggapan responden berdasarkan aspek rekayasa perangkat lunak maka didapatkan skor aktual yaitu 72,66\% berdasarkan hal tersebut maka kuliatas sistem yang dibuat dari segi aspek rekayasa perangkat lunak memiliki kriteria Baik. 
(C)2020 Ilmu Komputer Unila Publishing Network all rights reserved

2. Penilaian Terhadap Aspek Desain Aplikasi

Tabel 2. Penilaian Terhadap Aspek Desain Aplikasi

\begin{tabular}{|l|l|l|l|l|l|l|l|}
\hline \multicolumn{7}{|c|}{ Aspek Desain Sistem } \\
\hline \multirow{2}{*}{$\begin{array}{c}\text { Kriteria } \\
\text { Jawaban }\end{array}$} & \multirow{2}{*}{ Bobot } & \multicolumn{7}{|c|}{ Pertanyaan } & \multirow{2}{*}{ Total } \\
\cline { 3 - 8 } & & Soal 5 & Soal 6 & Soal 7 & \multicolumn{1}{c|}{ Soal 8 } & Soal 9 & \\
\hline SB & 5 & 0 & 0 & 2 & 3 & 0 & 5 \\
\hline B & 4 & 14 & 10 & 9 & 10 & 14 & 57 \\
\hline C & 3 & 1 & 5 & 4 & 2 & 1 & 13 \\
\hline K & 2 & 0 & 0 & 0 & 0 & 0 & 0 \\
\hline SK & 1 & 0 & 0 & 0 & 0 & 0 & 0 \\
\hline Total & & 59 & 55 & 58 & 61 & 59 & 292 \\
\hline Skor Aktual & 75 & 75 & 75 & 75 & 75 & 375 \\
\hline Skor Ideal & & 75 & & & & \\
\hline
\end{tabular}

$\%$ Skor Total $=\underline{292} \quad$ x $100 \%$

$=77,86 \%$

Dari hasil pengolahan data tanggapan responden berdasarkan aspek desain sistem maka didapatkan skor aktual yaitu $77,86 \%$ berdasarkan hal tersebut maka kuliatas sistem yang dibuat dari segi aspek desain sistem memiliki kriteria baik.

Tabel 3. Presentasi Rata-Rata

\begin{tabular}{|c|c|c|}
\hline No & Aspek & Presentasi Rata-Rata \\
\hline 1 & Rekayasa Perangkat Lunak & $72,66 \%$ \\
\hline 2 & Desain Sistem & $77,86 \%$ \\
\hline \multicolumn{2}{|c|}{ Total Rata- Rata } & $75,26 \%$ \\
\hline
\end{tabular}

Berdasarkan hasil dari rata rata per aspek penilaian kuesioner menunjukan nilai rata-rata untuk semua pertanyaan adalah 75,26\%. Sehingga apabila dimasukkan kedalam kategori persentase.

Tabel 4. Interval (Jarak) dan Interpretasi persen

\begin{tabular}{|l|l|}
\hline \multicolumn{1}{|c|}{ Interval } & \multicolumn{1}{c|}{ Keterangan } \\
\hline $0 \%-19,99 \%$ & Sangat Kurang Baik \\
\hline $20 \%-39,99 \%$ & Kurang Baik \\
\hline $40 \%-59,99 \%$ & Cukup \\
\hline $60 \%-79,99 \%$ & Baik \\
\hline $80 \%-100 \%$ & Sangat Baik \\
\hline
\end{tabular}

Web engineering sistem informasi pelayanan pengaduan online memiliki nilai kategori baik, sehingga sistem dikatakan layak dan menarik untuk digunakan sebagai web engineering sistem informasi pelayanan pengaduan.

\section{KESIMPULAN}

Berdasarkan uraian yang telah dipaparkan sebelumnya, maka dapat ditarik kesimpulan yaitu sistem informasi pelayanan pengaduan masyarkat dapat dijadikan sebagai sarana alternatif bagi masyarakat dalam pengaduan permasalahan yang dihadapi ke pemerintah P2TP2A. Sistem informasi pelayanan pengaduan masyarakat dapat 
(C2020 Ilmu Komputer Unila Publishing Network all rights reserved

mendata pendaftaran korban, pelaporan pengaduan masyakarat dan proses pelayanan, sehingga pemerintah P2TP2A dapat meningkatkan produktivitas di mata publik.

\section{UCAPAN TERIMA KASIH}

Terima kasih, penelitian ini dibiayai oleh DRPM Direktorat Jenderal Penguatan Riset dan Pengembangan Kementerian Riset, Teknologi, dan Pendidikan Tinggi tahun pelaksanaan 2020.

\section{DAFTAR PUSTAKA}

[1] Firmasyah C and Tohir C. 2018. "Sistem Layanan Pengaduan Masyarakat Lingkup Desa Gunungtanjung Berbasis Web Dan Sms Gateway Dengan Metode Antrian Fifo". JUMANTAKA.01:201-210.

[2] Nofyat, Adelina Ibrahim, and Arinsandy Ambarita. 2018. "Sistem Informasi Pengaduan Pelanggan Air Berbasis Website Pada Pdam Kota Ternate". IJIS. 03:10-19

[3] Pramono A. 2017. Sistem Pelayanan Pengaduan Online Berbasis Web Pada Pt.Fira Informatika Untuk Meningkatkan Layanan Konsumen. Semarang.

[4] Sulistiyani Hasiolan, Leonardo Budi Warso and M Mukeri. 2016. "Analisis Pengaruh Indeks Kepuasan Masyarakat Terhadap Pelayanan Publik Di Kelurahan Pudakpayung Kecamatan Banyumanik Kota Semarang". Semarang: Universitas Padjajaran.

[5] Tjiptono, Fandy. 2011. Strategi Pemasaran. Edisi 3. Yogyakarta : ANDI. 